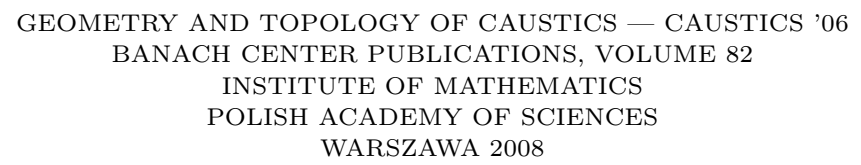

WARSZAWA 2008

\title{
CAUSTICS IN GREEK ANTIQUITY
}

\author{
ALAIN JOETS \\ Laboratoire de Physique des Solides, bât. 510 \\ Université de Paris-Sud, CNRS, UMR 8502, F-91405 Orsay Cedex, France \\ E-mail: joets@lps.u-psud.fr
}

\begin{abstract}
The word caustic was introduced by Tschirnhausen in 1686, in the Latin expression caustica curva. We show that the study of the optical caustics goes back well before, at least to the hellenistic period. We present a small Greek text, whose author is perhaps Geminus (1st cent. B.C.), describing an optical phenomenon called achilles. We show that the term achilles, which has appeared only once, to our knowledge, in the literature, means caustics by reflection. We complete the description of the achilles thanks to another text, a passage of the poem Argonautika of Apollonius Rhodius. Finally, we attempt to explain the association between the mythical hero Achilles and the optical phenomenon called achilles.
\end{abstract}

1. Introduction. The term caustic was introduced by W. Tschirnhausen, who studied the reflection of sun rays in a circular mirror. He observes that the concentration of light occurs not only at the focus, but also along an "entire curved line, which is produced by the intersections of reflected rays" [Tschirn82]. In fact, the name itself appears later in the Tschirnhausen's papers [Tschirn86], in the Latin expression caustica curva (caustic curve), quickly abbreviated to caustica. "Caustica" recalls the framework of Tschirnhausen's study: the problem of the burning mirrors, i.e. causticum speculum in Latin.

That the name caustica appears only in 1686 does not mean that caustics were unknown before. One finds examples of caustics in Huygens works (circa 1659), or in those of Maurolico, da Vinci, etc. We want here to go back in time as far as possible and to examine whether optical caustics were recognized by the Greeks in Antiquity. To our knowledge this question has not been considered yet.

2. The achilles. In his Géométrie Grecque, the French historian P. Tannery says that the Greeks studied "bright points" (points brillants) [Tannery]. Tannery does not use the

2000 Mathematics Subject Classification: Primary 01A20.

Key words and phrases: caustics, history.

The paper is in final form and no version of it will be published elsewhere. 


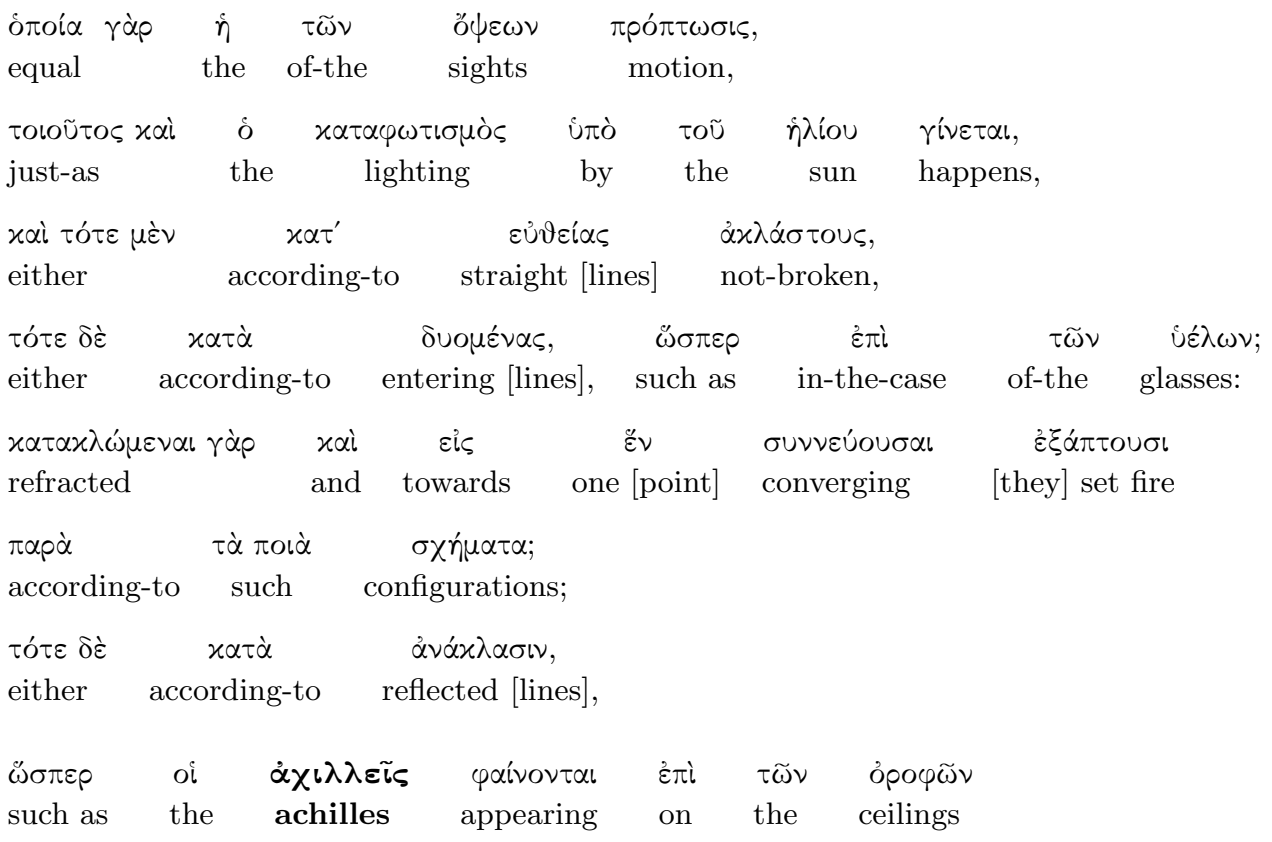

Table 1. Greek text and our interlinear translation of the passage containing the achilles. Some particles, like $\delta \grave{\varepsilon}$, are not translated, because they yield slight nuances, not important for the meaning of the text but difficult to translate. Conversely one Greek word may be translated by several words, linked here by the symbol "-". The implied words are written in brackets [...] in the translation.

name caustic and gives us to understand that he is talking about focuses. However he gives an interesting information: the Greek name for bright points is, rather strangely, "achilles" $(\dot{\alpha} \times\llcorner\lambda \lambda \varepsilon i \varsigma)$. For more information, Tannery invites the reader to consult two references, where the text of the achilles is given and translated: the Varice Collectiones edited by F. Hultsch [Hultsch] (1864) and a work of H. Martin on Heron of Alexandria [Martin] (1854). For the modern reader, a more accessible reference is the Heronis Alexandrini Opera, edited by J. L. Heiberg (1912) and re-edited more recently by Teubner [Heiberg] (1976). A digital copy of the last reference is now downloadable through the digital library Gallica on the site www.bnf.fr of the Bibliothèque Nationale de France.

The most ancient version of the text of the achilles dates from the Middle Ages. It is found in three manuscripts of the Bibliothèque Nationale de France: ms 2385, ms. 2475 and ms. 387, and also in other manuscripts of the libraries of Leiden, Oxford, El Escorial. Table 1 shows the text, accompanied with our interlinear word for word translation. A detailed philological analysis of the text will be published elsewhere [FederspielJoets].

The text belongs to the second part of a work entitled Origin of the geometric terms of Heron. Only the first part may be attributed to Heron (1st cent. A.D.). The second part is a compilation - "une compilation indigeste", says Martin - of several authors not cited (this is usual at that time). According to Martin, our text belongs to the Optika of 
Damianus (4th cent. A.D.). The modern philology attributes the text rather to Geminus (1st cent. B.C.) but the attribution is not certain. Some philologists prefer to present the author of our text as a "pseudo-Geminus". It remains that the text itself dates back at least to the 1st cent. B.C.

With the meaning of an optical phenomenon, the word achilles appears only once in the Greek literature, precisely in this text. In this sense, achilles is a hapax, a word having a unique occurrence in the ancient literature and thus generally difficult to translate. Heiberg translates achilles by "Sonnenreflexe" and Martin by "lumières mobiles auxquelles on donne le nom d'achilles" (moving lights called achilles).

In order to understand correctly the meaning of the passage, we have to recall the usual conception of the Greeks concerning the sight [Ronchi]. Rays are emitted by the eyes. These visual rays fall on objects and "sense" them, procuring the sensation of sight. Of course, the Greeks were aware that there exist also natural rays, like the sun rays.

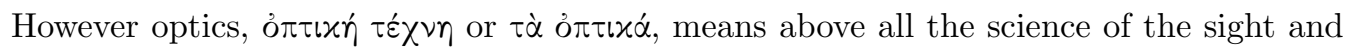
not the science of the natural rays. The aim of the text is precisely to show that what is known about the visual rays is also valid for the sun rays, despite their different nature.

In the first sentence the author says that the propagation (the transport, the progress, the motion) of the sun rays is totally similar to that of the visual rays. The remaining text specifies this general statement. Three situations implying sun rays are considered. The first one is the free, direct propagation. The author simply says that the rays are not-broken ( $\dot{\alpha}-x \lambda \dot{\alpha} \sigma \tau o \cup \varsigma)$. For the second and third situation, respectively the refraction $(x \alpha \tau \dot{\alpha}-x \lambda \alpha \sigma \iota \varsigma)$ and the reflection $(\dot{\alpha} \nu \alpha-x \lambda \alpha \sigma \iota)$, the author gives explicit examples. The example of the refraction of sun rays is provided by sun rays falling on glasses (or lenses): they converge towards a focus and set fire, when the glasses are correctly positioned. We find here the burning lens, a classical theme in the ancient scientific literature. Finally the example chosen for the reflection of the sun rays is an optical phenomenon called achilles by the author and appearing on the ceilings.

We claim that achilles correspond to caustics by reflection. We know that a generic congruence of rays, for example reflected rays, produces a caustic surface. The caustic is not directly observable. One usually uses a screen to observe the sections of the caustic with a plane. The whole caustic is then reconstructed by varying the position of the screen. It is clear that the ceiling plays precisely the role of a fixed screen. Moreover the ceiling suggests that the caustic is observed inside a house, the rays coming from the outside. In this situation, the optical contrast is better and makes the observation of the caustic easier.

The author says that the achilles are "appearing", but nothing is said about the cause of their appearance. We want now to answer this question with the help of another text, more ancient, belonging to the poetic literature: Argonautika of Apollonius Rhodius.

3. An optical metaphor in Argonautika of Apollonius of Rhodes. The poem Argonautika of Apollonius Rhodius (3rd cent. B.C.) is the story of Jason and the Argonauts and their quest for the Golden Fleece. In book III, the magician Medea falls in love with Jason. The poet lengthily describes her emotional turmoil. At some time, he 


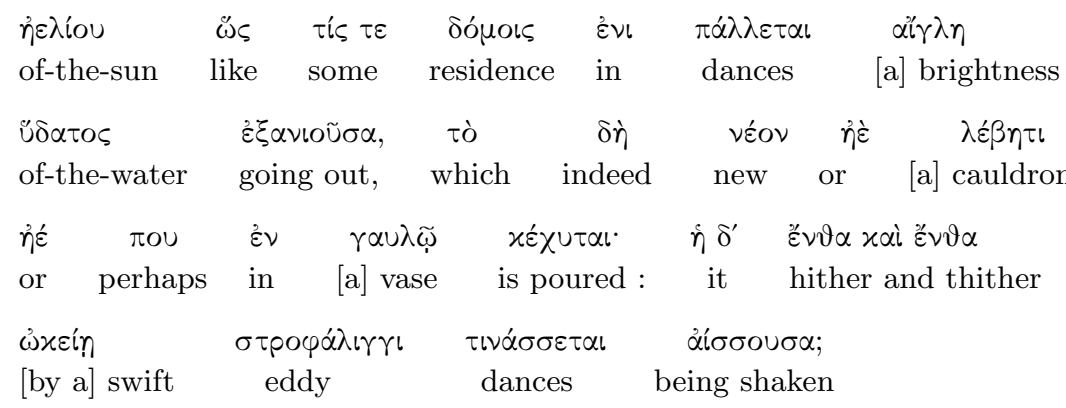

Table 2. Argonautika, book III, 756-759 of Apollonius of Rhodes. The apparent disorder in the position of the words comes from the fact that, in Greek, the ending is sufficient to express the relation between them, and from the necessity to follow the rules of the metrics. tò (verse 757)

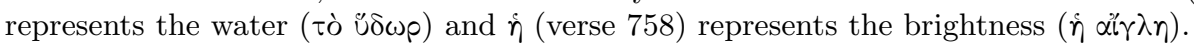

uses the rhetorical process of metaphor, making an analogy between the interior world of the emotions and the exterior world of the phenomena. The interest of this passage, for us, is that the metaphor is optical (see Table 2).

The emotion felt by Medea is compared with a sun brightness dancing in the house, when flung up from water. The scene then corresponds to the text of the achilles: the sun light enters the interior of a house and produces there rapidly changing luminous forms. The term achilles is not used. The poet talks only about sun brightness. The important point is that the reflector is described: water in a container. To express the reflection, Apollonius does not use the scientific term ( $\dot{\alpha} \nu \alpha \dot{x} \lambda \alpha \sigma \iota \varsigma)$, but a poetic term ( $\dot{\xi} \alpha \nu เ o \tilde{\sigma} \sigma \alpha)$, which has nearly the same meaning. The water is said to be just poured in a cauldron or a vase. In other words, the surface of the water is not at rest; it is continuously varying with the time. Finally, the poet describes roughly the phenomenon: the brightness, shaken by the eddy (of the water), appears here and there.

The metaphor of Apollonius usefully completes the scientific text of the achilles. It answers about the nature of the reflector: achilles may be produced by the reflection of the sun rays on a wavy reflecting surface (Fig. 1).

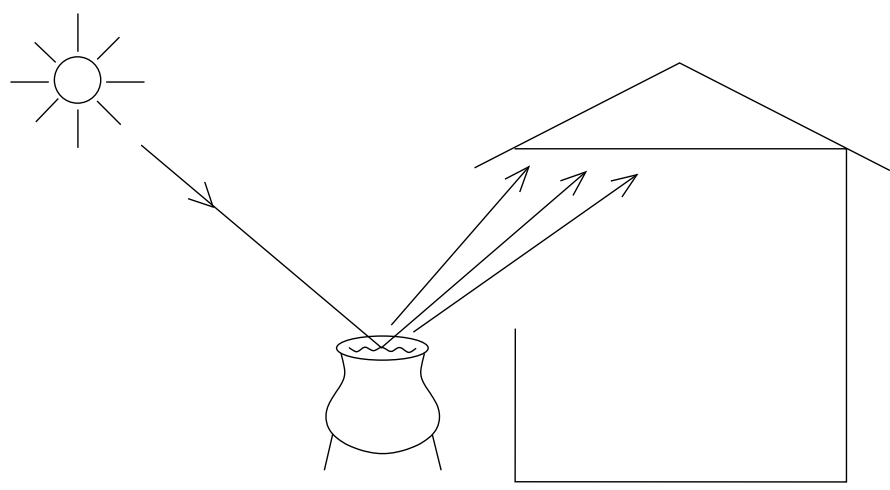

Fig. 1. The reflection of the sun rays on the water contained in a cauldron produces achilles on the ceiling. 
At this point we may try to explain the name achilles. The eponymous hero Achilles

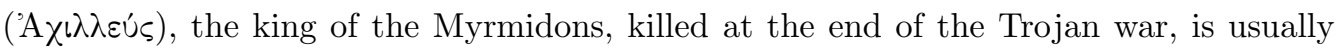

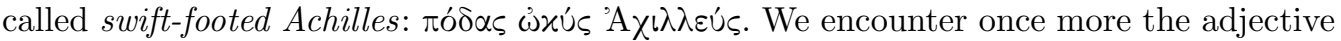

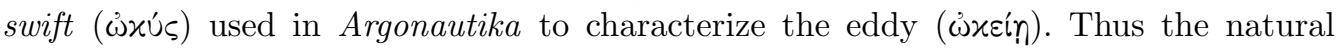
assumption is that the characteristic feature of the optical phenomenon called achilles is its variability in time, its fleetingness. The surface of the moving water varies continuously and a small variation in the orientation of a given surface element generates an appreciable variation in the section of the caustic by the plane of the ceiling. The optical form changes continuously and rapidly, as the warrior Achilles when he is running.

We note that, inversely, the word achilles is less appropriate for caustics by refraction. In effect, the bending of the rays towards the normal generates a spreading of the rays lesser than that in the case of a reflection. For this reason, one may believe that the achilles do not designate the caustics in general, but rather only the caustics by reflection. To our knowledge, there is no special name and even no description for the caustics by refraction in the Greek literature.

It is a pleasure for me to thank Prof. M. Federspiel, for his help in the translations and very interesting discussions about the Greek literature.

\section{References}

[FederspielJoets] M. Federspiel and A. Joets, Sur le phénomène optique des «achilles» dans la littérature grecque, in preparation.

[Heiberg] Heronis Alexandrini Opera quae supersunt omnia, vol. 4, J. L. Heiberg (ed.), B. G. Teubner, Stuttgart, 1976.

[Hultsch] Heronis Alexandrini geometricorum et stereometricorum reliquiae, F. Hultsch (ed.), Berlin, 1864.

[Martin] Th. Henri Martin, Recherches sur la vie et les ouvrages d'Héron d'Alexandrie, etc, Mémoires présentés par divers savants à l'Académie des Inscriptions et Belles-Lettres, Première Série, t. IV, 1854.

[Ronchi] V. Ronchi, Histoire de la lumière, Ed. Jacques Gabay, 1996.

[Tannery]

[Tschirn82]

P. Tannery, La Géométrie Grecque, Ed. Jacques Gabay, Sceaux, 1988.

W. Tschirnhausen [his name does not appear in the article], Nouvelles découvertes proposées à Messieurs de l'Académie Royale des Sciences, par ***, Journal des Scavans, 176, 1682; Acta Eruditorum, I, 364, 1682.

[Tschirn86] W. Tschirnhausen, Curva Geometrica qua se ipsam sui evolutione describit, Acta Eruditorum, IX, 169, 1686. 
